\title{
Novos formatos, antigos discursos: representações do surf no cinema brasileiro (199I-2006)
}

\author{
Rafael Fortes* \\ Victor Andrade de Melo**
}

\section{Resumo}

Este artigo tem por objetivo analisar os cinco filmes brasileiros lançados em circuito comercial e/ou festivais, entre 1991 e 2006, nos quais o surfe é o tema central: Manobra Radical (Elisa Tolomelli, 1991), Surf Adventures - O Filme (Arthur Fontes, 2001), Fábio Fabuloso (Pedro Cezar, Ricardo Bocão e Antônio Ricardo, 2004), Indo.doc (Leondre Campos e André Pires, 2006) e Tow In Surfing (Jorge Guimarães e Rosaldo Cavalcanti, 2006). O intuito é compreender as novas representações da modalidade, passada uma década do seu primeiro fluxo de crescimento no país (década de 1980). Ao final, conclui-se que, imersa em novas redes comerciais, a prática profissionaliza-se definitivamente, ainda que procure manter, pelo menos nos discursos, valores típicos de seu período de estruturação. Palavras chave: Cinema. Surfe. Brasil. Cultura. Juventude.

* Professor do Departamento de Filosofia e Ciências Sociais, Centro de Ciências Humanas e Sociais, Universidade Federal do Estado do Rio de Janeiro (UNIRIO), Rio de Janeiro-RJ, Brasil. Doutorado em Comunicação e Pós-Doutorado em História. Coordena o Sport: Laboratório de História do Esporte e do Lazer (UFRJ).E-mail: raffortes@hotmail.com

** Professor do Departamento de Didática e do Programa de Pós-Graduação em História Comparada, Instituto de História, Universidade Federal do Rio de Janeiro (UFRJ), Rio de Janeiro-RJ, Brasil. Doutorado em Educação Física e Pós-Doutorado em História e em Teoria Crítica da Cultura. Coordena o Sport: Laboratório de História do Esporte e do Lazer (UFRJ).E-mail: victora.melo@ uol.com.br 


\section{New formats, old discourses: representations of surfing in Brazilian cinema (199|-2006)}

\section{Abstract}

This article aims to analyze the five Brazilian films released in commercial cinemas and / or festivals between 1991 and 2006, featuring surfing as the main theme: Radical Maneuver (Elisa Tolomelli, 1991), Surf Adventures - The Movie (Arthur Sources , 2001), Fabio Fabulous (Pedro Cezar, Ricardo Bocão and Antonio Ricardo, 2004), Indo.doc (Leondre Campos and Andre Pires, 2006) and Tow In Surfing (Jorge Guimarães and Rosaldo Cavalcanti, 2006). The purpose is to understand the new representations of the sport, a decade after the first boom in Brazilian film, which happened in the 1980's. The conclusion is that, immersed in new business networks, surfing is definitely more professional, although the productions do try to keep, at least in discourse, values which were typical of the 1980's.

Keywords: Cinema. Surfing. Brazil. Culture. Youth.

\section{Nuevos formatos, viejos discursos: representaciones del surf en el cine brasileño (199|-2006) \\ Resumen}

En este artículo se pretende analizar las cinco películas brasileñas que estrenaran en el circuito comercial y / o festivales entre 1991 y 2006, donde el surf es el tema central: Maniobra Radical (Elisa Tolomelli, 1991), Surf Adventures - The Movie (Arthur Fontes, 2001), Fabio Fabuloso (Pedro Cezar, Ricardo Bocão y Antonio Ricardo, 2004), Indo.doc (Leondre Campos y André Pires, 2006) y Tow In Surfing (Jorge Guimarães y Cavalcanti Rosaldo, 2006). El objetivo es entender las nuevas representaciones del deporte, después de una década de su primera oleada de crecimiento en el país (en los 1980). Al final se concluye que, inmerso en nuevas redes de comercialización, el surf es sin duda más profesional, aunque las producciones traten de mantener, al menos en el discurso, valores típicos del periodo anterior. Palabras clave: Cinema. Surf. Brasil. Cultura. Juventud.

\section{Introdução}

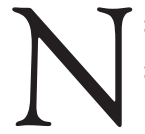

a cinematografia brasileira, pela primeira vez o surfe aparece em um longa-metragem em Garota de Ipanema (Leon Hirszman, 1967), mas é na transição das décadas de 1970 e 1980 que a modalidade aparece com mais frequência nas grandes telas, ocupando espaço de destaque em quatro obras: 
Nas ondas do surf, de Lívio Bruni Júnior (1978); Nos embalos de Ipanema (1978), Menino do Rio (1981) e Garota dourada (1983), os três de Antônio Calmon (MELO; FORTES, 2009). Além disso, ocupa lugar secundário ou aparece de maneira pontual em outras películas, como em Rockmania (Adnor Pitanga, 1986).

Esse aumento da presença do surfe nos filmes nacionais tem relação com o contexto dos anos 1980 . Nessa década, e em relativamente poucos anos, a modalidade deu um salto em termos de organização e comercialização, sedimentando-se como um esporte profissional, que movimenta bens econômicos e simbólicos muito além da esfera competitiva, inserida em um quadro em que crescentemente se valoriza a juventude, seja como parâmetro de vida (desejo de ser, permanecer ou, ao menos, parecer jovem), seja como mercado consumidor (FORTES, 2011).

Enquanto o esporte é elemento importante na celebração de "traços de [...] juvenilização" da sociedade contemporânea, o cinema é fundamental na criação de heróis e mitos juvenis (ENNE, 2010 , p.20). A articulação dessas características pode ser observada nos longas nos quais o surfe ocupa lugar central, marcando a construção de um imaginário típico ao redor da modalidade, cujo expoente maior é o personagem protagonista de Menino do Rio.

Nesse cenário, na verdade, o aumento da presença do surfe não se observa apenas no cinema. Estrutura-se um conjunto de produções midiáticas dedicadas a ele. Fluir, a revista brasileira mais vendida e longeva dedicada à modalidade, foi criada em 1983, dando sequência a experiências como a da pioneira Brasil Surf, lançada em 1975. Em 1986, havia no país oito publicações tendo a prática como assunto central (MIRA, 2001).

Da mesma forma, emissoras de rádio, como a Fluminense FM - de Niterói, criada nos anos 1970, e cuja programação voltou-se, no início da década seguinte, para o público jovem que ouvia rock, participaram da divulgação da modalidade ${ }^{1}$. Em programas específicos ou em boletins informativos (sobre as condições das ondas ou sobre as competições), o surfe apareceu na programação de estações de diversas cidades.

\footnotetext{
${ }^{1}$ Sobre a emissora, ver Mello (1992) e Silva (2008).
} 
Na televisão, destaca-se a presença de personagens ligados ao surfe em algumas novelas - traço que permanece até os dias atuais. O sucesso dos filmes de surfe dirigidos por Antônio Calmon levou a Rede Globo, principal emissora do país, a contratá-lo "por saber falar ao público jovem” (RAMOS, 1995, p.101). Criado por ele, Armação Ilimitada abordou com destaque a modalidade. No ar entre 1985 e 1988, marcou a época por seu caráter inovador na forma e no conteúdo. Antes disso, em 1983, estreou Realce, primeiro programa de esportes de ação da televisão brasileira, apresentado por dois surfistas: Ricardo Bocão e Antonio Ricardo. O programa permaneceu no ar por toda a década. Em 1991, muda o nome para OMBAK e migra para a MTV, então debutando no Brasil².

Passada uma década, como teria esse esporte permanecido no cinema nacional? Quais as representações da modalidade nesse momento posterior? Que teriam as películas a nos dizer sobre o formato contemporâneo da prática no país? Para responder tais perguntas, analisamos os longas-metragens nacionais que dedicaram atenção especial ao surfe, lançados entre os anos de 1991 e 2006, seja em circuito comercial ou em festivais: Manobra Radical (dir. Elisa Tolomelli, 1991), Surf Adventures - O Filme (dir. Arthur Fontes, 2001), Fábio Fabuloso (dir. Pedro Cezar, Ricardo Bocão e Antônio Ricardo, 2004), Indo.doc (dir. Leondre Campos e André Pires, 2006) e Tow In Surfing (dir. Jorge Guimarães e Rosaldo Cavalcanti, 2006).

Para alcance do objetivo, debruçamo-nos sobre o roteiro, a construção de personagens e os diálogos travados nos filmes, mas também sobre os aspectos não-verbais e estéticos, tais como recursos técnicos, sequências/cenas, entre outros. Além disso, levamos em conta aspectos relativos ao contexto de produção dos longas-metragens, que, acreditamos, dialogam diretamente com as configurações do campo esportivo gestado em torno do surfe. Nesse sentido, fez-se necessário entender as películas na sua articulação, como agentes e produtos, com a própria conformação da modalidade no cenário nacional.

\footnotetext{
${ }^{2}$ Para mais informações sobre Woohoo, ver < http://www.woohoo.com.br/aboutwoohoo>. Acesso em: 23 abr. 2012.
} 
Considerando que a mídia oferece constantemente "novas oportunidades de representação e comercialização" do esporte (ROWE, 2004, p.3), nosso objetivo é compreender as novas representações da modalidade presentes na produção audiovisual, passada uma década de seu primeiro fluxo de crescimento no Brasil.

Por entender que constroem discursos eminentemente para os membros da subcultura ${ }^{3}$ do surfe, não nos debruçaremos sobre outra interessante faceta da produção sobre o esporte: os filmes especializados (BOOTH, 2001), em geral lançados no formato de vídeos, desde os caseiros até os oficiais de campeonatos, bem como os promocionais (com alto orçamento financiado por patrocinadores e uso de avançados recursos técnicos). A circulação desse material varia muito, em geral sendo restrita aos adeptos da cultura do surfe: são vendidos ou baixados pela internet, ofertados como brinde na compra de revistas e/ou encontrados em raras locadoras especializadas.

Da mesma forma, pelo motivo oposto, por julgar que o esporte só é representado de forma ocasional, não nos debruçaremos sobre dois longas: O diabo a quatro (dir. Alice de Andrade, 2004); 1972 (dir. José Emílio Rondeau, 2006). Dedicaremo-nos, portanto, a discutir cinco longas que, a nosso ver, por suas características e circulação, ocuparam um espaço intermediário entre um público restrito de iniciados e o grande público, permitindo-nos captar as representações que cercavam a modalidade a partir da década de 1990.

\section{'Manobra Radical': um momento de transição}

Manobra Radical (Elisa Tolomelli, 1991) é protagonizado por dois surfistas e duas bodyboarders, interpretados pelos atletas João

\footnotetext{
${ }^{3}$ Subculturas são "estruturas menores, mais localizadas e diferenciadas" dentro da cultura de classe, referida como "cultura paterna”. Uma subcultura tem preocupações e características próprias, mas mantém, em maior ou menor grau, traços da cultura "paterna" (CLARKE et al. 1976, p.13-4). No caso do surfe, trata-se de uma subcultura vinculada às classes média e alta. Para uma discussão da aplicação do conceito à mídia do surfe, ver Fortes (2011, p.213-20). A relevância das subculturas esportivas é realçada tanto em trabalhos que analisam mídias de nicho (BOOTH, 2008; WHEATON; BEAL, 2003) quanto Meios de Comunicação de Massa (WENNER; GANTZ, 1989, p. 268).
} 
Capilé, Eraldo Gueiros, Glenda Kozlowski e Dominiquea Scudera. Além desses esportes, estão presentes na película o vôo livre e o skate, também apresentados como expressões de uma nova forma de viver a juventude no cenário urbano.

Os protagonistas usam roupas e pranchas estampando marcas de surfe e bodyboard, como Morey Boogie, Cyclone, Company, Quicksilver, Lightning Bolt. A Coca-Cola patrocina o campeonato vencido pelo personagem Guel (João Capilé). Os Meios de Comunicação ligados aos jovens e ao surfe estão presentes. Fluir aparece tanto como patrocinadora da referida competição quanto nas mãos de uma pessoa que, sentada na areia, assiste ao evento. Em uma passagem, ouve-se uma vinheta da Rádio Cidade (emissora FM do Rio de Janeiro), sintonizada no carro do quarteto.

Destacamos essa explícita vinculação com as empresas porque, se permanece nessa película uma representação idílica do surfe (espaço de liberdade e de contato com a "mãe-natureza”), típica das décadas de 1970 e 1980, uma nova questão se lança: como viver dedicando-se à modalidade? A trama gira em torno das dificuldades para resolver essa questão.

Logo no início do filme, Guel afirma: "o que mais quero na vida é viver do surfe e ser o melhor". Mais adiante, reitera: "o surfe é minha vida". Sem condições de se sustentarem como atletas profissionais, os personagens enfrentam problemas como a falta de dinheiro e as críticas dos pais, com quem moram e de quem dependem.

O conflito de gerações, aliás, aparece em vários momentos. Alegando preocupação com o futuro, um dos pais reclama que o filho largou a faculdade e só quer saber do esporte, sem preocupar-se com qualquer perspectiva profissional: "eu sou seu maior patrocinador”, afirma. Tais críticas são vistas pelos surfistas como incompreensão e "caretice". Esses desentendimentos são, nos filmes de surfe, uma expressão da condição de juventude, "ator social ainda não tão amarrado a estruturas e convenções" (ENNE, 2010, p.27). Esta observação é particularmente válida por se tratar, nesse caso, de jovens de classe média, que, por sua condição, contam com razoável margem de escolha na dinâmica 
entre realizações individuais e os constrangimentos de ordem coletiva (ENNE, 2010, p.25).

De qualquer forma, aparecem na película antigos temas relacionados à modalidade, apresentada como expressão de uma juventude que se nega a abandonar determinados valores ${ }^{4}$. Por exemplo, boa parte do enredo se desenvolve ao longo de duas viagens (para as regiões Sul e Nordeste; os protagonistas são cariocas), repletas de imagens da natureza: mar, vegetação, pôr-do-sol. Em Fernando de Noronha, observam-se golfinhos, peixes, água cristalina e até a ameaça de um tubarão. Na fala de um dos personagens, surfar nas ondas grandes desse arquipélago é a realização de um desejo: "paraíso dos meus sonhos, com minha gata e meus amigos".

O contraste entre o campo (natureza preservada) e o urbano (degradação) fica nítido quando os personagens retornam ao Rio de Janeiro. Em meio a viadutos congestionados, ficam presos no trânsito pesado e uma das protagonistas começa a tossir devido à fumaça e à poluição: a cidade é apresentada como sede de uma série de problemas insolúveis, restando apenas o refúgio temporário proporcionado pelas viagens ${ }^{5}$. Estas aparecem, portanto, dotadas de uma série de significados: fuga do ambiente hostil da metrópole; oportunidade de conviver com amigos e com a natureza, de começar e terminar relacionamentos e paixões, de acampar, de viver a vida sexual fora do domínio dos pais.

Outro tema recorrente é o choque de estilos de vida. Um conflito importante é gerado pela paixão entre um surfista e uma jovem grã-fina: "Paula, menina cheia de grana, e Guel, um surfista que parece mais um troglodita". Embora sejamos informados de que Paula já experimentou o voo livre, o que representava alguma proximidade e interesse com relação aos esportes na natureza, ela tem hábitos bem diferentes daqueles dos surfistas. $\mathrm{Na}$ viagem ao Nordeste, paga para todos passarem uma noite em um

\footnotetext{
${ }^{4}$ Enne (2010, p.27) afirma que atividades esportivas e consumo de produtos esportivos, entre outros comportamentos, remetem à busca de uma (suposta) eterna juventude, disseminada pela mídia corporativa e integrada à cultura do consumo. ${ }^{5}$ Para uma discussão sobre a dicotomia e articulações entre urbanidade e natureza, ver Dias (2008).
} 
hotel suntuoso, mas os amigos de Guel não se sentem à vontade ao jantarem no restaurante de luxo do estabelecimento. Embora ligada às classes média e alta, a subcultura do surfe tem em alta conta valores como despojamento e simplicidade.

Quando a moça engravida e o casal resolve ter o filho, o pai de Paula, numa tentativa de conciliação, oferece a Guel um emprego com bom salário em sua firma. Contudo, os problemas continuam: "eu falo português, ele fala surfês", queixa-se o empresário. Em determinado momento, engalfinham-se. O patrão afirma: "não sabe andar, não sabe nem falar!" Guel responde: "você é sogro de surfista! Meu pai era, eu sou, seu neto vai ser!".

$\mathrm{O}$ enredo se resolve com um final feliz: Guel vence um campeonato importante, o que lhe rende contrato de um ano com um patrocinador e passagem aérea para correr etapas do Circuito Mundial na Austrália. O clipe que encerra o filme mostra a vitória dos jovens e de seu amor pelo surfe - até o sisudo pai de Paula aparece se divertindo na praia.

A obra expressa os tempos de transição da sociedade brasileira. Ainda se sentiam os ares de esperança que foram tão fortes no cenário de redemocratização dos anos 1980 , bem como referências - já um tanto esmaecidas - da contracultura; todavia, novas questões, de caráter pragmático, já se impunham. Surf Adventures, lançado uma década depois, capta o resultado das negociações de expectativas que emergiram desse processo. Entre um e outro, a demora para o surfe voltar às telas. Assim, consideramos que Manobra Radical aproxima-se mais das representações da modalidade construída nos anos 1980 do que das observadas nos anos 2000 .

\section{'Surf Adventures’: o paraíso possível}

Surf Adventures - O Filme (dir. Arthur Fontes, 2001) foca a saga de surfistas brasileiros "em busca da onda perfeita". Divide-se em capítulos, cada um numa locação específica: Fernando de

${ }^{6}$ Referimo-nos, por exemplo, à campanha pelas eleições diretas para a presidência e às mobilizações durante os trabalhos da Assembleia Nacional Constituinte (1987-1988). 
Noronha, Ilhas Mentaway (Indonésia), Jeffrey's Bay (África do Sul), Havaí (EUA) e Mavericks (Califórnia, EUA).

Nos arquipélagos de Noronha e Mentaway, um grupo de atletas foi convidado pela produção do filme a viajar. No primeiro caso, destacam o "privilégio" de estar com amigos, livres dos problemas cotidianos, comendo peixe assado na brasa, tocando violão, tomando cerveja e pegando "altas ondas". Na mesma linha, nas ilhas da Indonésia, Teco Padaratz explica que a região, com coqueiros, mar transparente e ótimas ondas, é o paraíso com que um surfista, quando adolescente, sonha durante as aulas "chatas" da escola.

As representações idílicas da prática do surfe prosseguem, mas somente se tornam possíveis porque uma enorme estrutura comercial passou a cercar a modalidade. Longe de sugerirmos que há uma incoerência nessa conjugação, parece mais interessante investirmos na noção de ambivalência. Trata-se da expressão do possível, tendo em conta o novo quadro social e econômico.

A infraestrutura das produções, a presença de patrocinadores ${ }^{7}$ dispostos a investir em filmes de surfe, cujo objetivo é atingir o grande público, e a própria dinâmica da modalidade (brasileiros disputando o circuito mundial e contando com patrocínio de diversas marcas da indústria do surfe, tanto brasileiras quanto multinacionais) são expressões desta ambivalência: esse investimento técnico e financeiro combina-se com os valores que constituem o arquétipo da modalidade, que por sua vez teria como eixo de construção a negação de tudo aquilo que cerca esse grande investimento.

Após mais de uma década fora das telas e imerso nesse novo cenário, não surpreende que surfe seja abordado a partir de um viés didático. Pensamos tratar-se de estratégia para explicar ao grande público as peculiaridades (ou, ao menos, as representações simbólicas principais) da modalidade.

No novo contexto, portanto, entende-se o exaltar da relação competição-trabalho, que concede seriedade ao surfista, afastando antigas ideias de que se trata de um "desocupado". Para cada atleta apresentado, são listados os seus títulos conquistados como

${ }^{7}$ Por exemplo, Fábio Fabuloso foi financiado por Hang Loose (patrocinador principal), Oi e Nova Schin. 
profissional e amador (estadual, brasileiro, $\mathrm{WQS}^{8}$ ) e as vitórias em etapas do Circuito Mundial.

A valorização das conquistas é um indício da importância do aspecto competitivo do esporte, bem como do avanço do profissionalismo (afinal, mesmo entre os amadores, a maioria sonha profissionalizar-se e, para tanto, o principal requisito é o bom desempenho nos campeonatos). O filme, aliás, cobre uma etapa do então WCT (divisão principal do Circuito Mundial de Surfe promovido pela Associação de Surfistas Profissionais - ASP) na África do Sul, em 2000, quando Peterson Rosa e Teco Padaratz conquistaram o segundo e terceiro lugares, respectivamente.

Padaratz, um dos principais competidores brasileiros à época, narra o capítulo e mostra um pouco do que é ser profissional. Logo no início, explica: "aqui é o meu escritório". Afirma ainda que "o surfista brasileiro já é respeitado no mundo inteiro”. Segundo ele, competir é "o que mais gosto na vida". A frase é quase a mesma que vimos no filme anterior, com uma diferença: viver do surfe como profissional já era uma possibilidade concreta.

$\mathrm{Na}$ verdade, a despeito das mudanças, o filme revela a persistência de problemas e preconceitos, alguns deles citados por Peterson Rosa:

Competição é uma maneira que eu achei para mostrar pros meus pais, pros empresários, para o povo brasileiro que o surfe é um esporte de qualidade e não é coisa de vagabundo, drogado, que só quer ficar jogado na praia. É uma profissão de respeito como outra qualquer. Por isso eu comecei a entrar em competição, para mostrar pra vocês que se pode viver do surfe e que é uma profissão tão boa quanto ser médico, quanto ser um advogado irado, pode ganhar tão bem quanto esses caras.

A declaração se articula com a letra de "Não é sério", música do grupo Charlie Brown Jr.: "o jovem no Brasil nunca é levado a sério / sempre quis falar / nunca tive chance / tudo que eu queria estava fora do meu alcance”. Mais uma vez, o conflito de gerações

${ }^{8}$ World Qualifying Tour, espécie de "segunda divisão" do Circuito Mundial. O WQS foi disputado entre 1992 e 2009. 
surge como chave explicativa para a resistência em se aceitar o surfe como esporte, estilo de vida e profissão.

Vemos ainda a recuperação de antigos parâmetros que tão fortemente marcam a prática. Vários surfistas falam da procura da onda perfeita: "a busca é eterna. Se você falar que está satisfeito, você morreu” (Renan Rocha). Este desejo contínuo move o praticante a viajar para diferentes lugares na tentativa de encontrar novos mares ou repetir experiências anteriores, como é o caso da ida anual ao Havaí, uma espécie de peregrinação realizada de forma quase religiosa por muitos atletas entre os meses de dezembro e fevereiro.

Os entrevistados destacam a importância de estar lá para quem é surfista e quer ondas de verdade. Vários dizem que "todo mundo tem medo" das ondas grandes e perigosas e contam histórias de quedas, de ferimentos graves e de mortes, enquanto as imagens mostram sequências de tombos e pranchas quebradas. Narram a dificuldade de dormir com a adrenalina gerada pelo anúncio de um swell no dia seguinte. Constrói-se a ideia de que os sentidos e significados da prática permanecem, ainda que a estrutura tenha se modificado bastante, em função da adoção do profissionalismo.

filme termina como começou, com falas sobre o significado do surfe: "Tenho que estar surfando para estar vivendo, então espero surfar por muito tempo." (Fábio Gouveia); "descer uma onda acho que é a melhor coisa do mundo" (Raoni Monteiro). Ao fundo, ouve-se "Por enquanto" (Legião Urbana) na bela interpretação de Cássia Eller: "mudaram as estações, nada mudou (...) estamos indo de volta pra casa”. Um toque lírico em referência à melancolia típica do fim das viagens, mas também às boas lembranças que ficam. $\mathrm{O}$ ciclo se repete, a busca da onda perfeita nunca termina.

\section{'Fábio Fabuloso': um novo herói}

Fábio Fabuloso (dir. Pedro Cezar, Ricardo Bocão e Antônio Ricardo, 2004) é um documentário sobre a trajetória de Fábio Gouveia, atleta paraibano que detém alguns dos melhores resul- 
tados de brasileiros no Circuito Mundial, sendo, talvez, o mais importante da história do surfe nacional, no plano competitivo.

O intuito é claro: forjar um novo herói, ainda que meio sem jeito. Parentes e amigos que conviveram com Gouveia falam de sua trajetória desde quando faltava a aulas na escola e pegava ônibus e carona em caminhões de cana para chegar até Baía Formosa, praia do litoral potiguar onde aprendeu a surfar.

A história é contada dialogando com elementos que remetem a uma leitura da cultura nordestina - um indício de que se está à busca de forjar um herói tipicamente brasileiro: a literatura de cordel; o burrinho (um dos personagens da trama); gírias, expressões e narração (feita pelo pernambucano Pedro Cezar) cujo sotaque contrasta com o padrão estandardizado do pioneiro Nas ondas do surf (dir. Lívio Bruni, 1978), realizado quando o esporte buscava reconhecimento e legitimação, narrado por Sergio Chapelin, então apresentador do Jornal Nacional, da TV Globo, telejornal brasileiro de maior audiência.

Em Fábio Fabuloso, a modalidade se encontra consolidada no Brasil e a carreira de seu principal expoente é mostrada de forma criativa e brincalhona - coerente com o próprio personagem, aliás. A trilha sonora mistura ritmos regionais com batidas e efeitos eletrônicos.

São também entrevistados atletas brasileiros e estrangeiros que competiram e conviveram com Gouveia, além de fotógrafos internacionais. Ressalta-se seu estilo próprio de surfar: "o surfe dele é uma arte em cima da prancha" (Binho Nunes); a "linha de surfe" do paraibano é apresentada como uma "linha encantada".

Compondo a peculiaridade do personagem, são narradas situações inusitadas criadas ou vividas por Gouveia no Circuito Mundial, destacando-se sua dificuldade para falar inglês. Fábio parece ser apresentado não só como uma espécie de Chaplin ou Garrincha (que tem tudo para não dar certo, mas acaba tendo sucesso, uma representação cultural comum na história brasileira, que tem como um de seus exemplos notáveis Macunaíma), como também como um elo entre dois conjuntos de gerações: as 
antigas, cujos adeptos estavam interessados no surfe pelo surfe, e as recentes, com foco no profissionalismo e na competitividade ${ }^{9}$. Alfio Lagnado, proprietário da marca Hang Loose, lembra que condicionou o financiamento à participação de Flávio "Teco" Padaratz no Circuito Mundial da ASP à participação de Gouveia. Teco estaria mais preparado, "sabia viajar sozinho e falar inglês" e já havia morado nos EUA por seis meses; poderia, assim, "tutelar" o brilhantismo do heroico paraibano. Montou-se uma dupla de brasileiros que, pela primeira vez, se envolvia dessa forma com o cenário internacional da modalidade, disputando integralmente o circuito mundial a partir de 1989 . Os vínculos entre empresa e atleta superam duas décadas: ela ainda o patrocina ${ }^{10}$ e, como visto, foi a principal financiadora do filme.

Outro aspecto que marca a peculiaridade do herói é o fato de correr o Circuito Mundial acompanhado da esposa Elka (bodyboarder que conheceu dentro d'água) e dos três filhos do casal, atitude considerada inusitada pelos demais competidores. A disputa envolve muitas viagens e meses fora de casa, um problema sério para os atletas no que diz respeito às relações familiares e amorosas (BOOTH, 2005). Nas palavras do repetidas vezes campeão mundial Kelly Slater, em Surf Adventures: "é difícil sossegar, estabelecer-se num lugar e manter família e filhos. Há um lado egoísta e viciante na liberdade do surfe". Fábio, assim, uma vez mais foge do figurino absolutamente profissional, dando vazão a algo muito comum na cultura nacional, ainda mais forte por se tratar de um nordestino: a família se constitui em importante referência.

A produção se serve de extenso material de arquivo gravado desde os anos 1980. Para isso, certamente ajudou o fato de participarem da equipe técnica Ricardo Bocão e Antonio Ricardo, que trabalham há muitos anos produzindo mídia sobre a modalidade,

\footnotetext{
${ }^{9}$ Não estamos excluindo a existência de atletas interessados no profissionalismo no primeiro grupo, nem, no segundo, de adeptos cuja relação com a prática e com a subcultura passa longe (podendo inclusive se opor à) da comercialização. Referimo-nos a um espírito do tempo vigente e compartilhado em distintas épocas. ${ }^{10}$ Cf. < http://www.hangloose.com.br/equipe/fabio_gouveia.html >. Acesso em: 23 abr. 2012.
} 
especialmente na televisão. Passaram por suas mãos boa parte dos registros nacionais nesse período, sobretudo na década de 1980, quando era frequente cobrirem de forma exclusiva eventos, viagens e sessões de surfe.

Além disso, Fábio Fabuloso aproveita as facilidades de gravação, armazenamento e edição proporcionadas nos últimos anos pelos equipamentos digitais. Por exemplo, no uso de efeitos e na inserção de animações. Embora etapas como distribuição e veiculação permaneçam problemas graves para o cinema nacional, a maior oferta e o relativo barateamento dessas etapas ampliaram as possibilidades de se fazer filmes.

Parte da criatividade da narrativa pode ser atribuída à participação polivalente de Pedro Cezar, que narra, compõe músicas da trilha e atua no roteiro, direção e edição. Entre os recursos usados, citamos o uso de desenhos, quadrinhos, cortes, linhas e as explicações de palavras e expressões, dialogando com as produções do diretor gaúcho Jorge Furtado ${ }^{11}$.

Enfim, trata-se de um filme e de um surfista profissional que busca apresentar uma forma peculiar de se inserir no cenário internacional, sem abandonar certas representações do esporte e manifestando traços de uma suposta cultura nacional.

\section{'Indo.doc': antenado com o mundo}

Indo.doc (Leondre Campos e André Pires, 2006) guarda diferenças marcantes em relação às demais produções analisadas, a começar por seu planejamento. Quatro amigos estavam com viagem marcada para surfar na Indonésia. Pouco antes de partirem, houve o maior tsunami conhecido (26/12/2004) e, meses depois

\footnotetext{
${ }^{11}$ Em debate que contou também com a presença de Julio Adler (um dos editores do filme), Pedro "Pepê" Cezar afirmou que três filmes exerceram grande influência enquanto fazia Fábio Fabuloso: Ilha das Flores, O Fabuloso Destino de Amélie Poulin e O Auto da Compadecida. Informações dadas por Pedro "Pepê" Cezar e Julio Adler em debate no Cineclube Sport, no IFCS/UFRJ, Rio de Janeiro, em 21/6/2011. Para informações sobre o cineclube, ver <http://cineclubesport.wordpress.com $>$.
} 
(28/3/2005), um terremoto de grandes proporções. Mesmo assustados, resolveram viajar e "o que era uma surf trip acabou virando o Indo.doc", como informa o narrador. $\mathrm{O}$ quarteto passou seis meses lendo sobre os acontecimentos e planejando a aventura, realizada em meados de 2005: "a gente queria de alguma forma entender o que tinha acontecido e ajudar no que fosse possível”.

As tragédias mudaram o sentido e o roteiro da viagem. Alguns picos de surfe foram excluídos; em seu lugar, entraram os locais mais afetados pelo tsunami e pelo terremoto. Em um contexto repleto de dificuldades, inclusive para conseguir informações confiáveis sobre as áreas que pretendiam visitar, tornaram-se fundamentais os conhecimentos e contatos de um dos quatro, Felipe Ufo, que costuma passar vários meses por ano trabalhando na Ásia. Em Banda Aceh (local mais afetado pelo tsunami), relatam haver risco de sequestro por grupos rebeldes armados e falta de gasolina; em outra ilha, acamparam em uma cidade abandonada, sob terremotos, e tendo como companhia mosquitos transmissores de malária. O filme os retrata como pessoas com espírito aventureiro, humano e desbravador, mas preocupados com aspectos como segurança, logística e saúde.

Os quatro são protagonistas e câmeras. Como Fábio Fabuloso, Indo.doc se beneficia das possibilidades abertas pelos avanços tecnológicos. Isto se torna ainda mais evidente quando levamos em conta que foi realizado sem patrocínio ou apoio de empresas, ao contrário dos demais. Durante o filme e nos créditos finais, fica nítida a importância da internet no planejamento da viagem e na própria produção, permitindo acesso a textos, vídeos, imagens e outras informações.

Dentre as produções analisadas, é a que tem menos sequências de surfe. Impressionam bastante as cenas de efeitos do tsunami: um navio encalhado na terra, a três quilômetros da costa; encostas de morros cujas florestas foram varridas pelas ondas gigantes; acampamentos de refugiados à beira de estrada; caminhões do exército e de ONGs levando mantimentos e assistência. Ilhas sumiram, outras foram criadas. Cidades inteiras foram abandonadas. Apareceram, desapareceram, melhoraram ou pioraram as condições de surfe em 
vários locais. Face à tragédia, o texto da narração tece elogios à determinação, força e alegria do povo indonésio.

O filme busca demonstrar engajamento com a causa. Em Banda Aceh, dá voz a Aloy Fithrico, surfista que teve sua loja de surfe e sua pousada destruídas pelo tsunami. Guia e anfitrião do grupo, convoca os praticantes a voltar a frequentar o local, de forma que, com seu dinheiro, possam ajudar a população a reconstruir a vida. Um dos quatro (Elísio Tiúba) pinta a frente do café recém-montado por Fithrico; outro (Bruno Pesca) lhe dá de presente uma prancha.

Mais entrevistados destacam a importância do surfe para a economia e a vida locais. Em Asu, o brasileiro Alex Macabu, gerente de um surf camp, narra as dificuldades enfrentadas pela falta de surfistas; Mama Silvi, dona da única loja local, faz um apelo para que voltem a frequentar a ilha ${ }^{12}$.

$O$ filme informa ainda que houve surfistas participando da recuperação não apenas com os recursos gerados por sua presença, mas também por meio do voluntariado em associações como a Surfaid. É particularmente interessante o relato da médica da ONG International Medical Corps sobre três surfistas que ajudaram a tratar vítimas do terremoto, aprendendo e executando o trabalho de enfermeiros. Segundo ela, um deles, francês, apresentou-se explicando que "viajava todo ano para Nias [ilha indonésia] para surfar e queria ajudar e retribuir de alguma forma".

$\mathrm{O}$ filme termina com uma mensagem de esperança:

Nossa expedição tinha o objetivo de desbravar a Indonésia pós-tsunami. Ver a situação do local e como está sua recuperação. Mas mais do que isso, acho que trouxemos essa lição de que todos nós temos responsabilidade em tudo que acontece no planeta em que vivemos e que agindo em conjunto podemos gerar mudanças. Um ato de cidadania pode correr o mundo. E até um simples olhar, um sorriso, um gesto pode fazer uma grande diferença.

\footnotetext{
${ }^{12}$ Se, por um lado, o turismo pode funcionar como uma forma de a globalização alcançar o território e expandir o capitalismo a regiões e espaços antes "improdutivos" (NICOLÁS, 1994, p.91), por outro, temos aqui um exemplo de condições de vida intimamente associadas à presença de surfistas. A ausência de turistas representou, de acordo com o filme, a ruína local.
} 
A voz em off do narrador é acompanhada por um clipe destacando as pessoas entrevistadas - sorrindo. Os créditos finais incluem uma lista de sites de organizações para se colaborar com a recuperação da Indonésia e terminam com um "Visite a Indonésia!" Trata-se de uma aposta na solidariedade por meio do esporte, um enfoque inusitado para filmes que abordam o surfe.

\section{'Tow In Surfing': nos limites da emoção}

Tow In Surfing (Jorge Guimarães e Rosaldo Cavalcanti, 2006), apesar de narrado em inglês, é o primeiro filme brasileiro especificamente dedicado ao tow in, vertente em que o surfista conta com a ajuda de um jet ski (pilotado por um parceiro, também surfista) para entrar na onda e para ser resgatado ao fim dela. Tal apoio é necessário por se tratar de ondas imensas (com seis, oito, às vezes dez metros de altura), volumosas e rápidas demais para que o atleta entre e saia "remando".

Tow In Surfing é um documentário laudatório da prática que lhe dá nome, apresentada como extensão, aperfeiçoamento e futuro do surfe. Elenca as qualidades físicas e mentais (como coragem, concentração, respeito aos limites do mar e de si mesmo) e habilidades necessárias ao surfista (e piloto) para aderir ao tow in. Somam-se a esses atributos restrições de outras ordens, como a existência de poucos lugares com ondas gigantes; o alto custo ligado à infraestrutura necessária; e o número relativamente reduzido de dias do ano propícios à atividade.

Cheyne Horan, ex-surfista profissional, afirma que "a única razão pela qual não morrem muitas pessoas é porque é um esporte novo e há poucas pessoas praticando". Os entrevistados relatam o risco de vida constante da modalidade, enquanto são apresentadas cenas com quedas e salvamentos. $\mathrm{O}$ filme parece querer evidenciar determinadas dimensões que marcam o surfe: entre elas, a busca da onda perfeita e da adrenalina.

Ao que parece, a maior parte das cenas de ação foi gravada em dois períodos corridos: em Mavericks (Califórnia, EUA) e em um campeonato em Jaws (Havaí, EUA). Em nossa visão, as restri- 
ções inerentes ao tow in e a sua situação ainda incipiente afetaram a produção. A combinação de fatores necessários para reunir várias duplas no mar também vale para a infraestrutura necessária à gravação (com câmeras posicionadas em jet skis e helicópteros).

No tow in, o tamanho e velocidade das ondas fazem com que os surfistas as desçam quase "fugindo" da parte que está quebrando. Por sinal, esse é um ponto em comum com o início do surfe de remada, que, por muitas décadas, tinha poucas manobras - o mais comum era simplesmente descer-se a onda. Composto basicamente pela alternância de depoimentos explicativos e imagens de ondas enormes, a estrutura de Tow In Surfing lembra um pouco a de Nas ondas do surf. O predomínio masculino fica patente na película outro ponto em comum com o pioneiro Nas ondas do surf.

\section{Considerações finais}

Em linhas gerais, o surfe aparece no universo analisado como um esporte juvenil, saudável, excitante e alegre, que faz bem ao corpo e à mente. Há também um lado onírico, presente em todos os filmes e explicitado por Binho Nunes no início de Surf Adventures: "o surfe é a Terra do Nunca. A gente nunca vai crescer." Trata-se da ideia de que o surfista sempre vai querer praticar a modalidade, estar com amigos, viver novas experiências em busca da onda perfeita, de sensações, emoção e adrenalina.

Nesta linha de apresentar positivamente o esporte, problemas como o localismo pouco aparecem - exceto por breve passagem em Manobra Radical. Mesmo neste caso, a briga entre surfistas locais e de fora tem mais a ver com disputas por mulheres do que por ondas. Já o espaço dado às situações de perigo varia muito entre os filmes, desde algo pontual (um tubarão em Manobra Radical), passando por uma característica relativa ao lugar e às condições em que se surfa (Havaí e surfe de ondas grandes em Surf Adventures), chegando ao risco estrutural inerente à viagem realizada em Indo. doc ou à prática do tow in (Tow In Surfing).

Contrariamente às produções das décadas anteriores, no período de quinze anos analisado nesse estudo, a ficção é a 
exceção: apenas Manobra Radical (por sinal, o mais próximo, temporalmente, dos pioneiros) se enquadra na categoria. A produção se destaca pelo mergulho no universo dos jovens, explorando questões-chave como relacionamentos amorosos, gravidez indesejada (e a discussão sobre abortar ou não) e viagens (possibilidade de experimentar liberdade, conviver com os amigos e escapar da vigilância dos pais).

Meios de Comunicação ligados ao surfe e/ou ao público jovem participam do patrocínio, apoio e promoção dos filmes: Fluir (Surf Adventures, Fábio Fabuloso), portal de internet Waves (Fábio Fabuloso), emissoras de rádio FM voltadas para o rock (Surf Adventures). A maioria das músicas usadas é de artistas de sucesso na época em que as películas foram gravadas - quase sempre foi também lançado um disco com a trilha sonora. A indicação dos patrocinadores aparece explicitamente nos créditos iniciais ou finais, mas também há personagens e surfistas usando roupas e pranchas que estampam marcas, entre outras formas de merchandising.

A evolução tecnológica e a ampliação do uso de computadores se fazem notar de várias formas, incluindo o uso de desenhos e animações (destaque em Fábio Fabuloso) e imagens capturadas na internet (Indo.doc). À exceção de Manobra Radical, todos os demais utilizaram amplamente equipamentos digitais para captação e edição (montagem) das imagens.

Por fim, no que diz respeito a gênero, as mulheres têm escassa participação nas cenas e sequências diretamente ligadas ao surfe, ainda que haja exceções, como Andréa Lopes (Surf Adventures) e Maya Gabeira (Indo.doc). Apesar de Manobra Radical ter três personagens femininas que tenha papel relevante na trama, nenhuma delas é surfista (duas são bodyboarders).

Este artigo, de caráter exploratório, aponta para ao menos três possibilidades de investigação futura: a) explorar as representações do jovem nestas produções (algo que esboçamos, mas não foi possível aprofundar, dados os limites de um artigo); b) explorar o diálogo entre estas e outras produções cinematográficas e televisivas voltadas para a juventude interessada em surfe; c) explorar a recepção destas produções. 
Os filmes permitem leituras múltiplas (BARROS, 2011, p.187). Uns são mais fechados; outros, mais abertos. Certamente este artigo apresenta limitações interpretativas relativas a uma análise que coteja cada filme dentro de um conjunto (na medida em que foram produzidos independentemente uns dos outros; quem os coloca em um grupo/conjunto somos nós) e ao objetivo de discutir as representações do surfe (outras seriam possíveis, como as de juventude, da relação entre esporte e natureza, de gênero etc.).

O cinema é "um dos grandes agentes históricos da contemporaneidade" (BARROS, 2011, p.198). Constrói realidade, atua nos planos da cultura, da economia e da política, influindo neles e por eles sendo influenciado. Sabemos da importância do surfe e dos produtos a ele associados para as crianças, adolescentes e jovens consumidores e/ou admiradores. Neste encontro entre esporte, cultura e consumo, consideramos crucial olhar para o papel desempenhado pela mídia, apresentando possibilidades e estimulando direções para um público ávido por novidades e orientação. No caso do surfe, o cinema é elemento crucial para a construção de representações coletivas, integrando a dinâmica esporte-cultura. Nas palavras de Enne:

Adensando de forma definitiva o que já vinha fazendo desde a sua constituição, a cultura midiática será central no fornecimento de imagens e diretrizes para os sujeitos vivenciarem esse dramático jogo de personalizar-se sem perder, com isso, seus liames culturais (2010, p.23).

Reside aí uma das razões chave para estudar a Comunicação: por muitos motivos, e de muitas maneiras, ela é crucial para as pessoas. No caso, para a juventude brasileira, especialmente a juventude urbana.

\section{Referências}

BARROS, José D’Assunção. Cinema e história - considerações sobre os usos historiográficos das fontes fílmicas. Comunicação \& Sociedade, São Bernardo do Campo, a. 32, n. 55, p. 175-202, jan.-jun. 2011. Disponível em: < https://www.metodista.br/revistas/revistas-ims/index.php/CSO/article/ view/2324/2504>. Acesso em: 16 set. 2011. 
BOOTH, Douglas. Australian beach cultures: the history of sun, sand and surf. London: Frank Cass, 2001.

BOOTH, Douglas. Paradoxes of material culture: the political economy of surfing. In: NAURIGHT, John; SCHIMMEL, Kimberly S. (ed.) The political economy of sport. Basingstoke and New York, Palgrave Macmillan, 2005. p.104-25.

BOOTH, Douglas. (Re)reading The Surfers' Bible: the affects of Tracks. Continuum: Journal of Media \& Cultural Studies, [S.1.], vol. 22, n. 1, p.17-35, February 2008.

BUENO, Zuleika de Paula. Leia o livro, veja o filme, compre o disco: a produção cinematográfica juvenil brasileira na década de 1980. 2005. Tese (Doutorado em Multimeios) - Instituto de Artes, Unicamp, Campinas, 2005.

CLARKE, John et al. Subcultures, cultures and class. In: HALL, Stuart; JEFFERSON, Tony (ed.). Resistance through rituals: youth subcultures in post-war Britain. Hutchinson: London, 1976. p.9-75.

DIAS, Cleber Augusto Gonçalves. Urbanidades da natureza: o montanhismo, o surfe e as novas configurações do esporte no Rio de Janeiro. Rio de Janeiro: Apicuri, 2008.

ENNE, Ana Lucia. Juventude como espírito do tempo, faixa etária e estilo de vida: processos constitutivos de uma categoria-chave da modernidade. Comunicação, mídia e consumo, São Paulo, vol. 7, n. 20, p. 13-35, nov. 2010. Disponível em < http://revistacmc.espm.br/index.php/revistacmc/article/ view/300/208>. Acesso em: 17 ago. 2011.

FORTES, Rafael. O surfe nas ondas da mídia: esporte, juventude e cultura. Rio de Janeiro: Apicuri/Faperj, 2011.

MELLO, Luiz Antonio. A onda maldita: como nasceu a Fluminense FM. Niterói: Arte \& Cultura, 1992.

MELO, Victor Andrade de; FORTES, Rafael. O surfe no cinema e a sociedade brasileira na transição dos anos 1970/1980. Revista Brasileira de Educação Física e Esporte, São Paulo, v. 23, n. 3, julho-setembro 2009, p. 283-96. Disponível em: <http://www.scielo.br/scielo.php?script $=$ sci_arttext\&pid $=$ S1807$-55092009000300009 \& \operatorname{lng}=\mathrm{en} \& \mathrm{nrm}=\mathrm{iso}>$. Acesso em: 15 abr. 2013.

MIRA, Maria Celeste. O leitor e a banca de revistas: a segmentação da cultura no século XX. São Paulo: Olho d'Água/Fapesp, 2001. 
NICOLÁS, Daniel Hiernaux . Tempo, espaço e apropriação social do território: rumo à fragmentação na mundialização? In: SANTOS, Milton; SOUZA, Maria Adélia A. de; SILVEIRA, Maria Laura (org.). Território: globalização e fragmentação. 2. ed. São Paulo: Hucitec/Anpur, 1994. p. 85-101.

RAMOS, José M. Ortiz. Televisão, publicidade e cultura de massa. Petrópolis: Vozes, 1995.

ROWE, David. Introduction: mapping the media sports cultural complex. In:

(ed.). Critical Readings: Sport, Culture and the Media. Maidenhead: Open University Press, 2004. p.1-22.

SILVA, Heitor Luz da. Rádio FM, Rock e Rio de Janeiro: uma análise das estratégias de incursão da "Fluminense Maldita" e da "Cidade do Rock" no domínio das guitarras. 2008. Dissertação (Mestrado em Comunicação) - Programa de Pós-Graduação em Comunicação, Universidade Federal Fluminense, Niterói, 2008.

THORPE, Holly. Beyond "Decorative Sociology": Contextualizing Female Surf, Skate, and Snow Boarding. Sociology of Sport Journal, [s.1.], v. 23, p. 205-228, 2006.

WENNER, Lawrence A.; GANTZ, Walter. The Audience Experience with Sports on Television. In: WENNER, Lawrence (ed.). Media, Sports \& Society. Newbury Park: Sage, 1989. p. 241-69.

WHEATON, Belinda; BEAL, Becky. 'Keeping It Real': Subcultural Media and the Discourses of Authenticity in Alternative Sport. International Review for the Sociology of Sport, London, v. 38, n. 2, p. 155-176, 2003.

Recebido: 07.09.2012

Aceito: 20.02.2013 